\title{
ASSESSMENT OF DENDROCHRONOLOGICAL YEAR-OF-DEATH ESTIMATES USING PERMANENT SAMPLE PLOT DATA
}

\author{
EILEEN L. JONES and LORI D. DANIELS*
}

Department of Geography, University of British Columbia, 1984 West Mall, Vancouver, British Columbia, Canada V6T 1 Z2

\begin{abstract}
We combined crossdating with permanent sample plot (PSP) data to assess the precision and accuracy of year-of-death (YOD) estimates obtained by crossdating white spruce and lodgepole pine snags and logs. Crossdating indicated trees died between 1833 and 2006. Comparison of crossdated YOD dates for pairs of samples $(n=121)$ showed that $90 \%$ of YOD estimates were within 10 years of each other. Of 100 trees that died after PSP establishment, 59 YOD dates were within the documented interval of death (IOD). Of the 41 inaccurate dates, $77 \%$ of YOD dates preceded the IOD midpoints and error increased with time since death. Regression models increased the accuracy of spruce YOD estimates for trees that had been dead $\geq 17$ years, but the corrections were modest (e.g. +5 at 50 years). For pine, the correction models increased accuracy regardless of time since death and corrections were greater than those for spruce (e.g. +4 and +11 at 5 and 50 years, respectively). Precision and accuracy errors resulted from many factors including loss of bark, wood decay, lack of ring formation prior to tree death, and human error. Our results reinforce the need for multiple lines of evidence when reconstructing tree deaths using tree rings. We urge others with access to PSP data to assess the quality of crossdated YOD estimates. Ideally, PSP re-measurements intervals would be short and consistent, facilitating comparisons through time and among genera and locations.
\end{abstract}

Keywords: crossdating, year of death, accuracy, precision, permanent sample plots, interval of death, Pinus contorta, Picea glauca, snags, logs.

\section{INTRODUCTION}

Coarsewood, including snags (standing dead trees) and logs (uprooted trees, snapped trees, snapped tops, and large branches on the ground), serves myriad ecological functions, but its dynamics are not thoroughly understood (Harmon et al. 1986). In order to effectively incorporate coarsewood into stand dynamics models, we require species- and ecosystem-specific understandings of mortality and coarsewood decay rates and processes. Understanding coarsewood decay dynamics requires knowledge of snag and log persistence (i.e. time since tree death) and thus year of tree death. Year of death (YOD) can be estimated directly using re-measurements of permanent sample plots and indirectly using dendrochronological analysis.

*Corresponding author: lori.daniels@ubc.ca
Permanent sample plot (PSP) studies provide direct observations of dead trees during plot remeasurements; however, the precision of YOD dates is restricted by the length of the re-measurement interval. YOD dates from PSP studies are either reported as an interval (e.g. Vanderwel et al. 2006) or assumed to be the midpoint of the remeasurement interval in which a tree died (e.g. Newberry et al. 2004). In many PSP networks, the target re-measurement interval is every five years (Lewis et al. 2004), but because of resource constraints, re-measurement intervals can vary considerably in length among both plots in a network and within individual plots. For example, mortality studies of permanent sample plots in Denmark revealed variation in re-measurement intervals of 1 to 35 years (Nord-Larsen 2006).

In contrast, dendrochronological analysis provides year-of-death estimates at an annual resolution. YOD estimates are obtained by cross- 
dating the ring-width series of an individual snag or log against a master chronology, which allows the assignment of a calendar year to the outermost ring on the sample. This technique assumes that the outermost ring indeed reflects the year of tree death, which may not be the case when samples are decayed or missing bark (Mast and Veblen 1994; Daniels et al. 1997). In addition, the outermost ring may not reflect the year of tree death if a tree is suppressed or declining prior to death (Takaoka 1993; Cherubini et al. 2002) or if it exhibits asymmetrical cambial mortality (Amoroso and Daniels 2010).

Dendrochronological methods have been widely used in studies of coarsewood dynamics to determine YOD dates for snags and logs (e.g. Daniels et al. 1997; Storaunet and Rolstad 2004; DeLong et al. 2005, 2008), but dendroecologists rarely have the opportunity to assess the quality of these estimates through comparisons with PSP inventory data. Many studies acknowledge the potential sources of error inherent in working with decayed wood but, to our knowledge, the magnitude of error associated with crossdating decayed wood has never been quantified.

In this study, we use a combination of crossdating and independent PSP data to assess the precision and accuracy of YOD estimates of white spruce (Picea glauca [Moench] Voss) and lodgepole pine (Pinus contorta Dougl. ex Loud. var. latifolia Engelm.) snags and logs. We addressed two groups of research questions:

1. How precise are YOD estimates? Within a single tree (snag or log), how similar are YOD dates from pairs of cores (snags) or pairs of radii (logs)? When there is a mismatch in YOD dates, what factors contribute to this discrepancy?

2. How accurate are the YOD estimates? How do YOD estimates compare to the reported interval of death dates from the permanent sample plot data? What percent of YOD dates occur within the reported interval of death? What is the magnitude of error of YOD estimates?

We applied the outcomes of the accuracy assessment to develop regression models for improving crossdated estimates of the YOD of spruce and pine coarsewood for our study area. Ultimately, our intent is to understand the magnitude of different sources of error in YOD, providing a more precise and accurate understanding of coarsewood dynamics.

\section{METHODS}

\section{Study Area}

This study was conducted in the Hinton Wood Products Forest Management Area of the Foothills Research Institute near Hinton, Alberta $\left(53^{\circ} 24^{\prime} 09^{\prime \prime} \mathrm{N}, 117^{\circ} 34^{\prime} 33^{\prime \prime} \mathrm{W}\right)$, east of the Rocky Mountains. In this region, upland forests are characterized by closed-canopy coniferous stands, dominated by lodgepole pine, white spruce, and black spruce (Picea mariana (Mill.) BSP). The landscape is a mosaic of mixed-successional pine, pine-white spruce, and white spruce-black spruce stands, created by stand-initiating fires with a historical return interval of 100 years (Beckingham et al. 1996).

Between 1956 and 1961, North Western Pulp and Paper (now Hinton Wood Products) established a network of $c a$. 3,000 permanent sample plots (PSPs) that included a range of forest types and stages of stand development (Hinton Wood Products 2006). At plot establishment, all live trees were tagged and tree status (live, snag, log, or missing) was recorded at each re-measurement. The target re-measurement interval for old-growth coniferous PSPs is every five years; however, as many as 34 years have lapsed between successive measurements.

This study focused on five old-growth white spruce (hereinafter "spruce") and five old-growth lodgepole pine (hereinafter "pine") PSPs (Table 1). In the Alberta foothills, old-growth characteristics develop $c a$. 160 years after a standreplacing disturbance (Morgantini and Kansas 2003). To be included in this study, the PSPs had to meet three criteria:

1. The last stand-replacing disturbance was at least 160 years prior to program establishment in 1956.

2. No stand-level biotic or abiotic disturbances had been noted in the PSP records. 
Table 1. Attributes of old-growth white spruce (SA-SE) and lodgepole pine (PA-PE) sites. All data except location were provided by Hinton Wood Products.

\begin{tabular}{lccccl}
\hline Site & Site Cluster & Location & Stand Origin & Plot Establishment & \multicolumn{1}{c}{ Measurement Dates } \\
\hline SA & S1 & $53^{\circ} 39^{\prime} 26^{\prime \prime} \mathrm{N}, 118^{\circ} 26^{\prime} 28^{\prime \prime} \mathrm{W}$ & 1741 & 1958 & $1958,1966,1999,2008$ \\
SB & $\mathrm{S} 2$ & $53^{\circ} 20^{\prime} 14^{\prime \prime} \mathrm{N}, 117^{\circ} 36^{\prime} 29^{\prime \prime} \mathrm{W}$ & 1770 & 1956 & $1956,1962,1996,2002,2008$ \\
SC & $\mathrm{S} 3$ & $53^{\circ} 39^{\prime} 31^{\prime \prime} \mathrm{N}, 118^{\circ} 23^{\prime} 33^{\prime \prime} \mathrm{W}$ & 1741 & 1959 & $1959,1966,1999,2008$ \\
$\mathrm{SD}$ & $\mathrm{S} 3$ & $53^{\circ} 39^{\prime} 36^{\prime \prime} \mathrm{N}, 118^{\circ} 23^{\prime} 33^{\prime \prime} \mathrm{W}$ & 1741 & 1959 & $1959,1966,1999,2008$ \\
SE & $\mathrm{S} 3$ & $53^{\circ} 39^{\prime} 31^{\prime \prime} \mathrm{N}, 118^{\circ} 23^{\prime} 41^{\prime \prime} \mathrm{W}$ & 1741 & 1959 & $1959,1966,1999,2008$ \\
$\mathrm{PA}$ & $\mathrm{P} 1$ & $53^{\circ} 47^{\prime} 35^{\prime \prime} \mathrm{N}, 118^{\circ} 12^{\prime} 03^{\prime \prime} \mathrm{W}$ & 1768 & 1959 & $1959,1966,1999,2008$ \\
$\mathrm{~PB}$ & $\mathrm{P} 1$ & $53^{\circ} 46^{\prime} 30^{\prime \prime} \mathrm{N}, 118^{\circ} 12^{\prime} 03^{\prime \prime} \mathrm{W}$ & 1768 & 1959 & $1959,1966,1999,2008$ \\
$\mathrm{PC}$ & $\mathrm{P}$ & $53^{\circ} 46^{\prime} 26^{\prime \prime} \mathrm{N}, 117^{\circ} 51^{\prime} 57^{\prime \prime} \mathrm{W}$ & 1741 & 1961 & $1961,1966,1996,2002,2008$ \\
$\mathrm{PD}$ & $\mathrm{P} 2$ & $53^{\circ} 46^{\prime} 27^{\prime \prime} \mathrm{N}, 117^{\circ} 52^{\prime} 04^{\prime \prime} \mathrm{W}$ & 1741 & 1961 & $1961,1966,1996,2002,2008$ \\
$\mathrm{PE}$ & $\mathrm{P} 3$ & $53^{\circ} 44^{\prime} 41^{\prime \prime} \mathrm{N}, 118^{\circ} 23^{\prime} 48^{\prime \prime} \mathrm{W}$ & 1710 & 1958 & $1958,1966,1983,1996,2002,2008$ \\
\hline
\end{tabular}

3. At the last re-measurement, PSPs were at least $65 \%$ spruce or pine by both basal area and stem density.

We randomly selected 10 study plots (five spruce, five pine) that were accessible and met our criteria (Figure 1, Table 1). All plots have stand origin dates of 1710 to 1770 , based on interpretation of fire and forest cover maps. Six of the plots (SA, SC-SE, PA, PB) were re-measured four times (including the initial measurement and 2008),

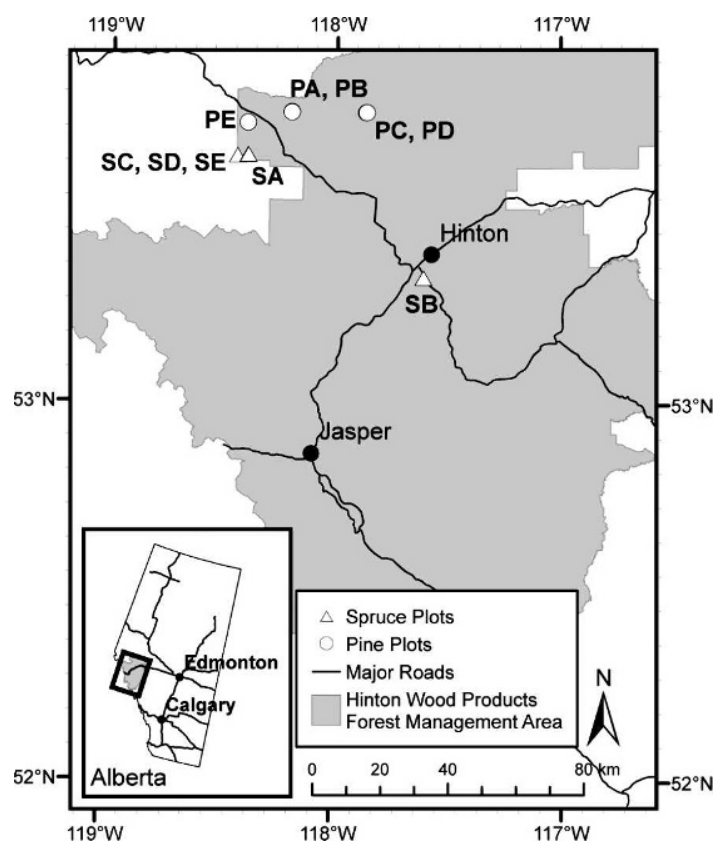

Figure 1. Old-growth white spruce (SA-SE) and lodgepole pine (PA-PE) study plots in the Hinton Wood Products Forest Management Area of the Foothills Research Institute. three were re-measured five times (SB, PC, PD), and one was re-measured six times (PE). Remeasurement intervals ranged from 5 to 34 years with an average of $14.0 \pm 3.7$ (mean \pm standard deviation) years.

\section{Field Sampling}

To build species- and site-specific tree-ring chronologies, we extracted increment cores from living canopy-dominant trees at all six PSP clusters. Trees were sampled outside the boundaries of the PSPs to ensure the integrity of these long-term monitoring plots and, when there was more than one study plot in a PSP cluster (e.g. CS3; see Table 1), we sampled trees between the plots when possible. We extracted a single core per tree, $\leq 30 \mathrm{~cm}$ above the ground. We cored $c a .30$ trees per PSP cluster, depending on core quality.

We located all trees in each plot and identified each as living or dead, and subsequently as a snag or log. For each piece of coarsewood, we identified species and assessed decay class, using a nine-stage decay classification for snags (Table 2; Thomas et al. 1979) and a five-stage decay classification system for logs (Table 2; Maser et al. 1979). We restricted this study to spruce coarsewood in spruce sites and pine coarsewood in pine sites.

All snags included in this study were $\geq 7.0 \mathrm{~cm}$ in diameter at breast height (dbh) and either had their original tag or their identity could be established using the PSP data. We collected two increment cores per tree from a stratified random 
Table 2. Snag and log decay classes based morphology and structural integrity of the bole (after Thomas et al. 1979, Maser et al. 1979).

\begin{tabular}{|c|c|c|}
\hline $\begin{array}{l}\text { Coarsewood } \\
\text { Type }\end{array}$ & $\begin{array}{c}\text { Decay } \\
\text { Class }\end{array}$ & Characteristics \\
\hline \multirow[t]{9}{*}{ Snag } & 1 & Live; in good health \\
\hline & 2 & Live; declining \\
\hline & 3 & Dead; bark intact, sound wood, fine branches present, needles may be present \\
\hline & 4 & Dead; bark sloughing, sound wood, fine branches absent, sapwood beginning to soften \\
\hline & 5 & Dead; bark mostly absent, heartwood sound, sapwood rotting \\
\hline & 6 & Dead; bark absent, heartwood beginning to rot, sapwood rotting, broken top \\
\hline & 7 & Dead; decomposing, heartwood and sapwood rotting, still standing \\
\hline & 8 & Dead; decomposing, mostly downed material, heartwood and sapwood rotting \\
\hline & 9 & Dead; decomposing stump \\
\hline \multirow[t]{5}{*}{$\log$} & 1 & Solid log, sapwood and heartwood sound; branches present; needles may be present; bark fully intact \\
\hline & 2 & Structurally-sound log, sapwood beginning to decompose; bark has begun to fall off \\
\hline & 3 & Sections of sapwood in advanced stages of decay; log round and supports own weight; little bark remaining \\
\hline & 4 & $\begin{array}{l}\text { Heartwood decay; log resting on ground and cannot support its own weight; pieces easily slough off; moss } \\
\text { often present on outer surface }\end{array}$ \\
\hline & 5 & Advanced decay; log incorporating into the forest floor; powdery texture \\
\hline
\end{tabular}

subsample of snags. Up to four snags per decay class were sampled at each site, limited by the number of snags in each represented decay class. Where possible, cores included the bark and avoided basal scars and other anomalies. We collected increment core samples from a total of 75 snags.

Logs included uprooted trees, snapped trees, snapped tops, and large branches. Tags were found on only $31 \%$ of the logs, and the study was restricted to these tagged logs. To be included, a log had to be $\geq 7 \mathrm{~cm}$ in diameter at mid-length, $\geq 1 \mathrm{~m}$ in length, and at least $50 \%$ of the log had to be within the plot boundaries. Using a chainsaw, we collected a single cross-sectional disc from each of a stratified random subsample of logs. Up to four logs per decay class were sampled at each site, limited by the number of tagged logs in each represented decay class. Samples were taken from the most structurally sound section of the $\log$ and included bark and solid sapwood where possible. Cross-sections were reinforced with duct tape before sampling to ensure integrity of the sample. We collected cross-sectional discs from a total of 57 logs.

\section{Dendrochronological Analyses}

We mounted all cores on wooden supports and reinforced discs from logs with hot glue as needed. All samples were sanded using progressively finer sandpaper to 600 grit before viewing the rings with a microscope (Stokes and Smiley 1996). To develop master chronologies, each core was visually crossdated and ring-width series were measured to the nearest $0.001 \mathrm{~mm}$ using a Velmex bench interfaced with MeasureJ2X V3.2.1 measuring software (VoorTech Consulting, Holderness, NH). The ring-width series were statistically crossdated using the program COFECHA (Holmes 1983; Grissino-Mayer 2001) and accurately dated and highly correlated cores were combined in site- and species-specific master chronologies. The chronologies were standardized using the horizontal standardization option in the program ARSTAN (Cook 1985).

All cores from snags were measured to the nearest $0.001 \mathrm{~mm}$ and two radii were measured per disc from logs. Radii were selected based on series length and the presence of bark and intact sapwood. To estimate year of tree death for both snags and logs, we used COFECHA (Holmes 1983; Grissino-Mayer 2001) and the Time Series Analysis Programme (TSAP-Win, Rinn 2003) to statistically crossdate the ring-width series and assigned a calendar year to the outermost ring of each sample. To verify crossdating, we used the Math Graph function of TSAP-Win to visually compare the ring-width series of the individual 
cores against the standardized ring-width series of the appropriate chronologies.

\section{Precision: YOD Estimates from Pairs of Cores and Pairs of Radii}

We compared the outermost ring date from pairs of cores and radii to identify discrepancies in crossdated YOD dates related to sample quality and decay, missing bark, narrow outer rings, and asymmetrical cambial death. We labeled each outermost ring date in a pair; the more recent of the two dates became year 1 ( core $_{1}$ or radius $\left._{1}\right)$ and the other date became year (core $_{2}$ or radius $\left._{2}\right)$. Precision error was the difference between year ${ }_{1}$ and year ${ }_{2}$. By definition, it was always a positive value.

\section{Accuracy: YOD Dates versus PSP Data}

When there was a discrepancy in YOD dates from pairs of cores or pairs of radii, we used the more recent YOD date to estimate the year of tree death. Time since death was calculated as 2008 minus the YOD, and is equivalent to snag and $\log$ age (the number of years a tree had been dead). For trees that died after plot establishment (1956-1961, Table 1), we verified YOD dates by comparing them to the recorded interval of death (IOD) from the PSP data. We restricted further analyses to trees that died after plot establishment as we could not calculate the magnitude of error of YOD estimates for trees that died prior to plot establishment. The IOD was defined as follows: the upper limit was the re-measurement year in which the tree was recorded as dead and the lower limit was the preceding re-measurement year. We compared the estimated YOD date with the recorded IOD dates for each snag and log and calculated the number of YOD dates that occurred within, before, and after the observed IOD dates.

The magnitude of error for accuracy was also assessed. Because exact years of death were not recorded in the PSP data and census intervals varied in length, we defined accuracy error in two ways. First, the IOD midpoint minus the YOD estimate yielded positive/negative error values for
YOD estimates that preceded/followed the IOD midpoint. This was a "conservative" estimate of accuracy error as it assumed the midpoint of the IOD was the actual YOD and that all departures from that year represent an error. Second, the crossdated YOD estimates that were within the IOD were classified as accurate, and YOD estimates that were before or after the IOD were classified as inaccurate. Accuracy error (IOD midpoint minus the YOD estimate) was calculated only for inaccurate YOD estimates. This was a "liberal" estimate of error as it was calculated using only the subset of observations outside the IODs.

\section{Corrections of Accuracy Error}

We used linear regression to quantify the degree to which accuracy error increased with time since death, then developed models to correct the crossdated YOD estimates and improve accuracy. These analyses were conducted for the two genera using the snag and log data combined to maximize the sample size. Four correction models were tested for each genus:

$$
\mathrm{YOD}_{1}=\mathrm{YOD}+\left(\mathrm{b}_{0}+\mathrm{b}_{1}(\mathrm{YOD})\right)
$$

where, $\mathrm{YOD}_{1}$ is the corrected YOD; YOD is estimated by crossdating; and, $b_{0}$ and $b_{1}$ are the coefficients from the genera-specific linear regression of accuracy error on year of death using the "conservative" error estimates (e.g. IOD midpoint minus YOD, for all YOD estimates).

$$
\mathrm{YOD}_{2}=\mathrm{YOD}+\left(\mathrm{b}_{0}+\mathrm{b}_{1}(\mathrm{YOD})\right)
$$

where, $\mathrm{YOD}_{2}$ is the corrected YOD; and, the coefficients $b_{0}$ and $b_{1}$ are from the generaspecific linear regression of accuracy error on year of death using the "liberal" error estimates (e.g. IOD midpoint minus YOD, for inaccurate YOD estimates only).

$$
\mathrm{YOD}_{3}=\mathrm{p}_{\text {accurate }}(\mathrm{YOD})+\mathrm{p}_{\text {inaccurate }}\left(\mathrm{YOD}_{1}\right)
$$

where, $\mathrm{YOD}_{3}$ is the corrected YOD; $\mathrm{p}_{\text {accurate }}$ is the proportion of YOD estimates determined by crossdating (YOD) that were within the 
Table 3. Summary statistics for site-specific white spruce (CS1-CS3) and lodgepole pine (CP1-CP3) master ring-width chronologies.

\begin{tabular}{ccccccc}
\hline Chronology & $\begin{array}{c}\text { Number of } \\
\text { Trees }\end{array}$ & $\begin{array}{c}\text { Mean Series } \\
\text { Length (years) }\end{array}$ & $\begin{array}{c}\text { Chronology } \\
\text { Start }\end{array}$ & $\begin{array}{c}\text { Chronology } \\
\text { End }\end{array}$ & $\begin{array}{c}\text { Series } \\
\text { Intercorrelation }\end{array}$ & $\begin{array}{c}\text { Average Mean } \\
\text { Sensitivity }\end{array}$ \\
\hline S1 & 29 & 258 & 1695 & 2007 & 0.61 & 0.19 \\
S2 & 30 & 96 & 1889 & 2007 & 0.60 & 0.21 \\
S3 & 28 & 262 & 1709 & 2007 & 0.64 & 0.18 \\
P1 & 26 & 171 & 1774 & 2007 & 0.50 & 0.17 \\
P2 & 32 & 163 & 1730 & 2007 & 0.49 & 0.21 \\
P3 & 26 & 111 & 1718 & 2007 & 0.52 & 0.18 \\
\hline
\end{tabular}

IOD; $p_{\text {inaccurate }}$ is the proportion of crossdated YOD estimates that preceded or followed the IOD; and, $\mathrm{YOD}_{1}$ is the corrected YOD derived from the linear regression of the "conservative" error estimates using equation (1).

$\mathrm{YOD}_{4}=\mathrm{p}_{\text {accurate }}(\mathrm{YOD})+\mathrm{p}_{\text {inaccurate }}\left(\mathrm{YOD}_{2}\right)$

where, $\mathrm{YOD}_{4}$ is the corrected $\mathrm{YOD}$, and $\mathrm{YOD}_{2}$ is the corrected YOD derived from the linear regression of the "liberal" error estimates using equation (2).

We used two criteria to evaluate the quality of the original crossdated YOD estimates and corrected YOD estimates derived from each model for each genus. First, we determined the percentage of corrected YOD estimates that were within the IOD and deemed accurate (large percentage values indicate high accuracy). Second, we conducted goodness of fit tests using a chi-squared $\left(\mathrm{X}^{2}\right)$ test statistic in which the YOD estimates were the observed values and the IOD midpoints were the expected values (low $\mathrm{X}^{2}$ values indicate high accuracy).

\section{RESULTS}

\section{Chronology Development}

We developed six chronologies, three for spruce and three for pine. Summary statistics for the chronologies indicated that trees within a site responded similarly to variation in environmental factors (Table 3). Series intercorrelation values ranged from $0.49-0.64$, suggesting that crossdating within each chronology was robust and suitable for estimating years of tree death.

\section{Precision: Comparison of YOD Estimates within Trees}

We successfully crossdated and obtained YOD estimates for 71 of 75 snags, which ranged from 1840-2006 for spruce and 1866-2002 for pine. YOD estimates were obtained for both cores for 69 snags. The YOD dates from 13 pairs of cores from spruce snags were the same, while the remaining 19 pairs differed by $1-16$ years, $90 \%$ of which differed by $\leq 5.9$ years (mean $=2.3$, median $=1.0$ years; Figure 2). For pines, five pairs of cores had the same YOD dates and 32 pairs differed by $1-63$ years $($ mean $=8.8$, median $=$ 3.0 years). Three pairs of cores from pine snags were outliers that differed by 52, 54, and 63 years. After re-evaluating these cores we confirmed the second core of each pair was missing its bark and/ or sapwood and the structure and colour of the wood indicated decayed sapwood in two cores. The other pairs of cores from pine snags differed by less than 24 years, $90 \%$ of which differed by $\leq 8.7$ years (mean $=4.6$, median $=3.0$ years), which was similar to the other coarsewood types.

We successfully crossdated and obtained YOD estimates for 54 of 57 logs, which ranged from 1833-2008 for spruce and 1906-2002 for pine. YOD estimates were obtained for both radii for 52 logs. The YOD dates from nine pairs of radii from spruce logs were the same, while the remaining 20 pairs differed by $1-32$ years, $90 \%$ of which differed by $\leq 8.2$ years (mean $=4.0$, median $=1.0$ years; Figure 2). For pines, four pairs of radii had the same YOD dates and 19 pairs differed by $1-18$ years, $90 \%$ of which differed by $\leq 8.0$ years (mean $=3.9$, median $=3.0$ years $)$. Scatter plots of time since death $v$ s. precision error 

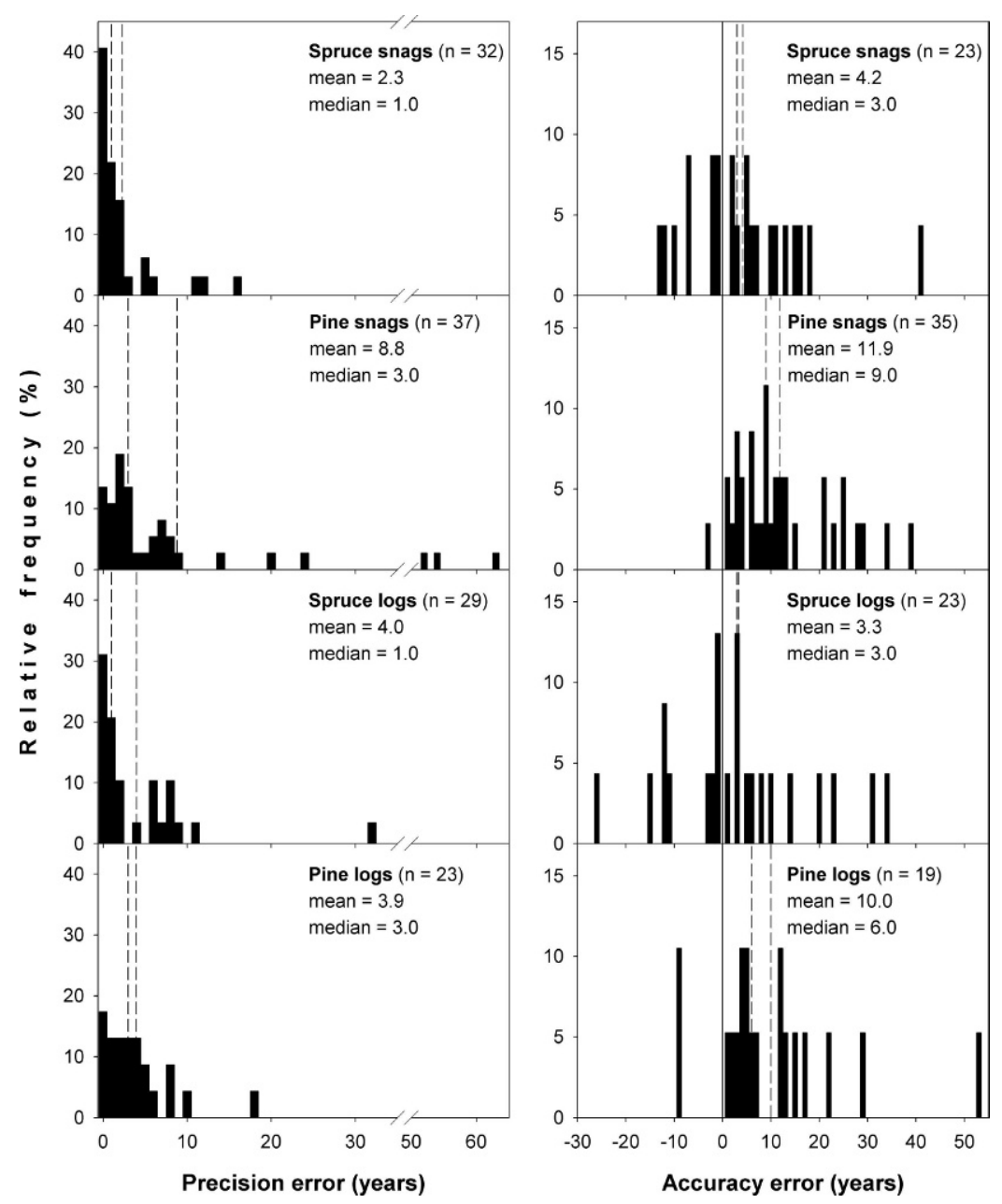

Figure 2. Precision and accuracy errors by genera and coarsewood type. Precision error is the difference in pairs of YOD dates from the same tree and is always positive. Accuracy error is the IOD midpoint minus the YOD estimate and includes positive (YOD precedes the IOD midpoint) or negative (YOD follows the IOD midpoint). In each panel, the mean and median values are indicated by the vertical dashed lines. In the accuracy error panels, the midpoint is indicated by the vertical solid line.

$\left(\right.$ year $_{1}-$ year $_{2}$ ) did not reveal a trend between the magnitude of error and time since death for both genera and coarsewood types (data not shown).

\section{Accuracy: Assessment YOD Dates versus PSP Data}

For the subset of 58 snags that died after the establishment of the PSPs, YOD estimates for spruce snags $(70 \%$ within the IOD) were more accurate than for pine snags (49\% within the IOD) (Figure 3). On average, YOD estimates preceded the IOD midpoint by 4.2 years for spruce (accuracy error $=-13$ to 41 years) and 11.9 years for pine (accuracy error $=-3$ to 39 years; Figure 2). Most YOD estimates occurred before the IOD midpoint (61 and 94\% of spruce and pine, respectively), suggesting that the corresponding time-since-death values are overestimated.

Similar to the snags, for the subset of $42 \operatorname{logs}$ that died after the establishment of the PSPs, YOD estimates for spruce logs $(74 \%)$ were more accurate than pine logs (47\%) (Figure 3). Spruce YOD estimates preceded the IOD midpoint by 3.3 years on average (accuracy error $=-23$ to +34 years), with $57 \%$ of YOD estimates preceding 


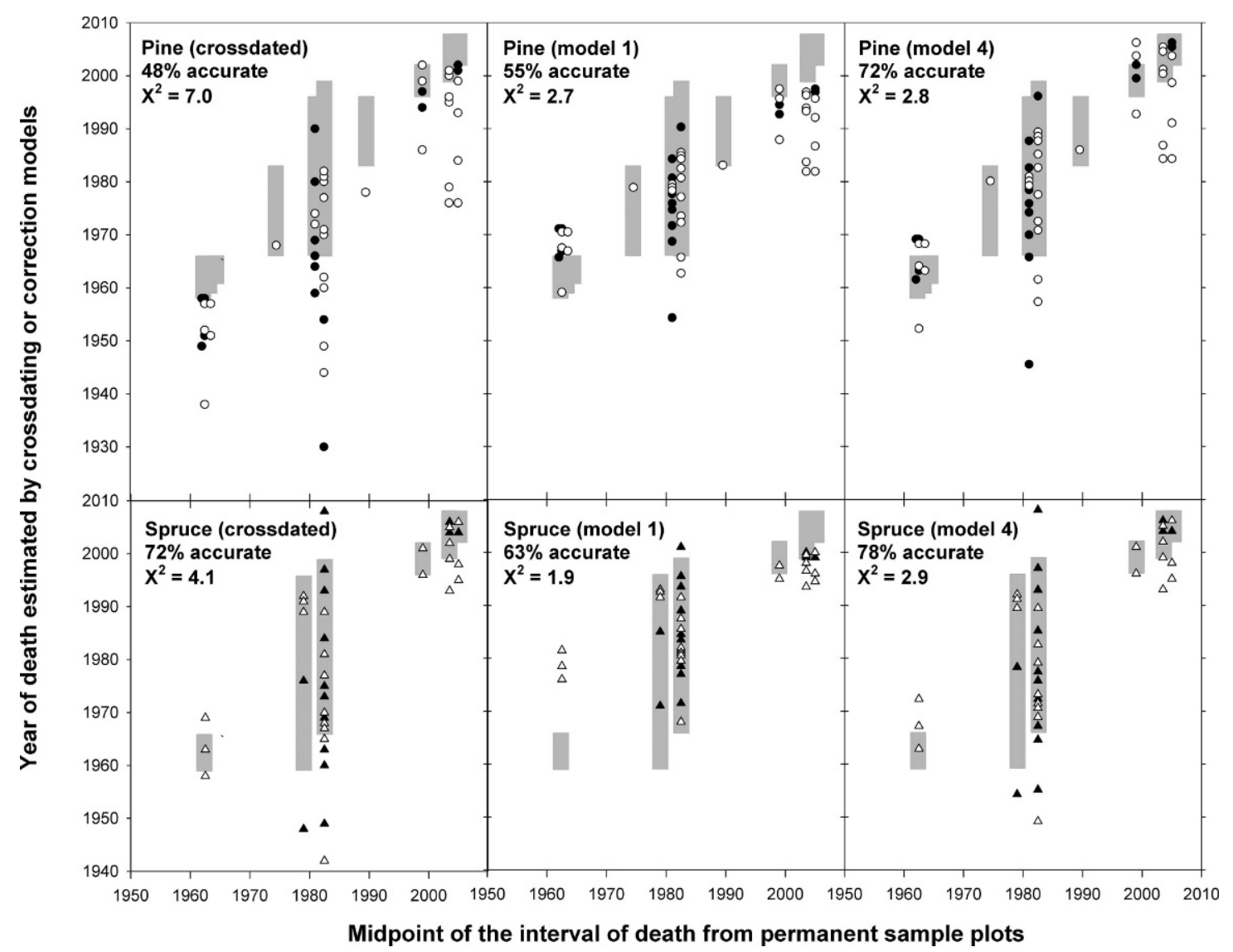

Figure 3. Comparison of intervals of death (IOD) from permanent sample plots and year of death (YOD) determined by crossdating for pine (top, circles) and spruce (bottom, triangles). Genera-specific regression models (equations (1) and (4)) were used to derive corrected YOD estimates (middle and right panels). In each panel, the shaded boxes depict the re-measurement intervals for the permanent sample plots. White and black symbols are snags and logs, respectively. Symbols located in the shaded boxes represent accurate YOD estimates relative to the IOD. The $\mathrm{X}^{2}$ goodness of fit statistic quantifies difference between each YOD estimate and the midpoint of the IOD.

the IOD midpoint. Most (90\%) of the pine YOD estimates preceded the IOD midpoint and resulted in average overestimates of time since death of 10.0 years (accuracy error $=-9$ to +53 years).

YOD determined by crossdating commonly preceded the recorded IOD for all re-measurement intervals, including recent intervals (1996-2002, 1999-2008, 2002-2008) and the early intervals (1958-1966, 1961-1966; Figure 3). Accuracy error increased significantly with time since death for pine and spruce (Figure 4). The regression models for pine met the assumptions of homogeneity of variance and normality; the models for spruce did not meet the assumption of normality even after transforming the data. For spruce, the normal probability plots for the untransformed data approximated a linear relationship but included small departures, which limits predictive inferences from the coefficients and confidence limits but allows descriptive interpretation (Neter et al. 1996), as follows. For both genera, correction models 1 and 2 systematically underestimated YOD values from recent intervals and overestimated YOD values from the early intervals (Figure 3). The underestimates were particularly pronounced for spruce as the regression models included negative accuracy error values for YOD $\geq 1992$ (Figure 4), so that corrected YOD values preceded the crossdated YOD values, falsely indicating the trees died before the last ring was 


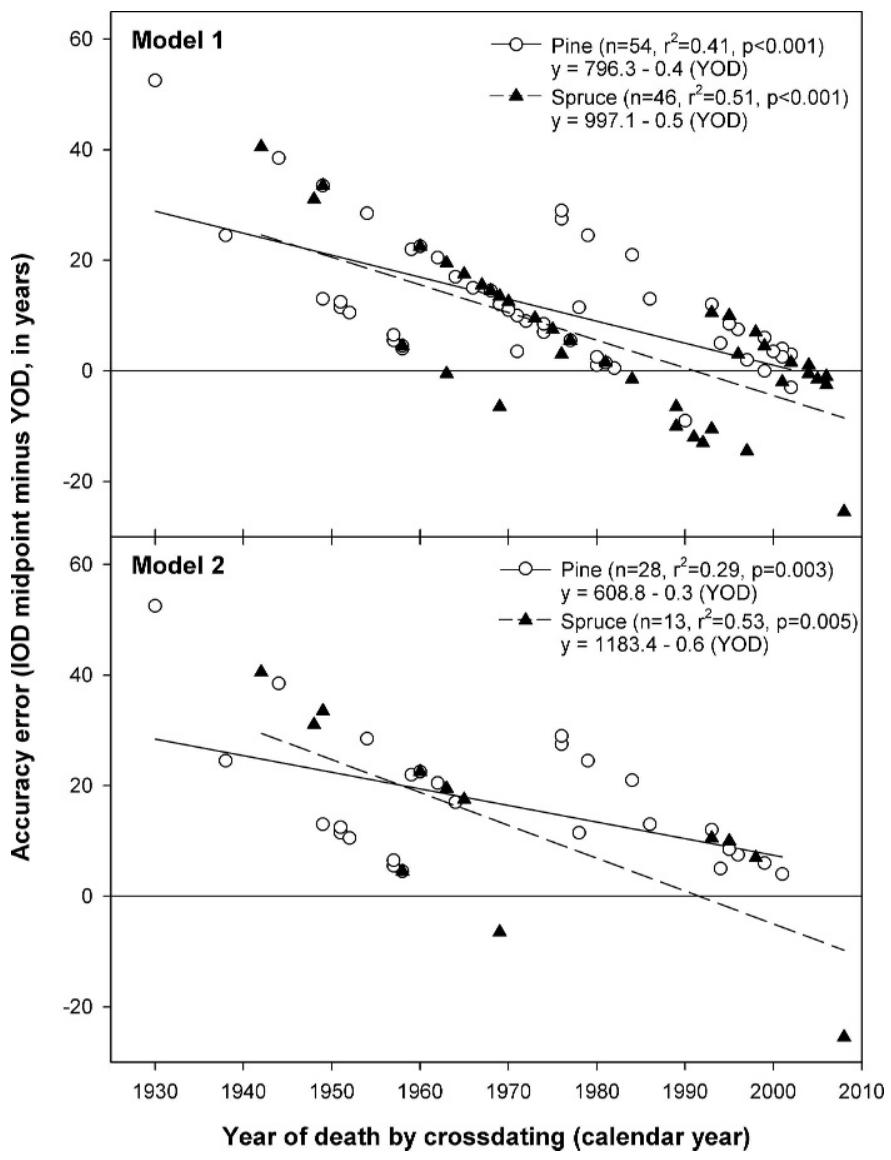

Figure 4. Genera-specific regressions of accuracy error relative to year of death (YOD). Regression model 1 (top) was based on the "conservative" errors for all snags and logs of pine (circles, solid line) and spruce (triangles, dashed line). Regression model 2 (bottom) was based on "liberal" errors for the subset of snags and logs for which crossdated YOD was outside the interval of death.

formed. We addressed this bias by applying correction models 3 and 4 only to spruce with YOD $\leq 1991$ (e.g. time since death $\geq 17$ years). Model 4, the model derived using the "liberal" estimates of error and weighted to account for accurate crossdated YOD estimates, yielded the highest accuracy and lowest $\mathrm{X}^{2}$ values, indicating it provided the best corrections for YOD for both genera (Figure 3, Table 4). The improvements for spruce that had been dead $\geq 17$ years were modest, with corrections of +2 and +5 years (based on model 4) for coarsewood that had been dead 25 and 50 years, respectively. For pine, the improvements applied to all coarsewood and were more substantive. Corrections were $+4,+7$ and +11 for pine coarsewood that had been dead 5, 25 and 50 years, respectively.

\section{DISCUSSION}

\section{Precision of YOD Estimates}

By combining our crossdating outcomes with the independent data from permanent sample plots, we assessed the precision and accuracy of estimated years of death for white spruce and lodgepole pine trees. In our study, the variation in outer-ring dates of different radii within a single snag or log represents the precision of year of death estimates. Overall, 31 of 121 pairs of samples were precise, meaning the YOD estimates matched for pairs of cores from snags and radii within logs. The differences between cores and radii measured the magnitude of error in precision within individuals. These differences were generally small, with $90 \%$ within 10 years of each other, 
Table 4. Comparison of models to improve accuracy of year-of-death (YOD) estimates. A high percent accuracy and low $\mathrm{X}^{2}$ value indicated the best model for accurately estimating YOD.

\begin{tabular}{|c|c|c|c|}
\hline Genus & Model & Accuracy $(\%)$ & Fit $\left(\mathrm{X}^{2}\right)$ \\
\hline \multirow[t]{5}{*}{ Pine } & YOD $=$ determined by crossdating (no correction) & 48 & 7.0 \\
\hline & $\mathrm{YOD}_{1}=\mathrm{YOD}+(796.3-0.4(\mathrm{YOD}))$ & 55 & 2.7 \\
\hline & $\mathrm{YOD}_{2}=\mathrm{YOD}+(608.8-0.3(\mathrm{YOD}))$ & 57 & 3.0 \\
\hline & $\mathrm{YOD}_{3}=(0.48)(\mathrm{YOD})+(0.52)(\mathrm{YOD}+(796.3-0.4(\mathrm{YOD}))$ & 61 & 4.1 \\
\hline & $\mathrm{YOD}_{4}=(0.48)(\mathrm{YOD})+(0.52)(\mathrm{YOD}+(608.8-0.3(\mathrm{YOD}))$ & 72 & 2.8 \\
\hline \multirow[t]{5}{*}{ Spruce } & YOD $=$ determined by crossdating (no correction) & 72 & 4.1 \\
\hline & $\mathrm{YOD}_{1}=\mathrm{YOD}+(997.1-0.5(\mathrm{YOD}))$ & 63 & 1.9 \\
\hline & $\mathrm{YOD}_{2}=\mathrm{YOD}+(1183.4-0.6(\mathrm{YOD}))$ & 58 & 4.4 \\
\hline & $\mathrm{YOD}_{3}=(0.72)(\mathrm{YOD})+(0.28)(\mathrm{YOD}+(997.1-0.5(\mathrm{YOD}))$ & 78 & 3.0 \\
\hline & $\mathrm{YOD}_{4}=(0.72)(\mathrm{YOD})+(0.28)(\mathrm{YOD}+(1183.4-0.6(\mathrm{YOD}))$ & 78 & 2.9 \\
\hline
\end{tabular}

indicating a relatively high degree of precision for most snags and logs. The small differences within pairs of YOD estimates were expected because we were primarily working with trees that had retained their tags, and we aimed to collect samples that included the bark or sound sapwood, meaning that at least part of the tree was not substantially decayed. As illustrated by the three pine snags with precision errors exceeding 50 years, snags and logs in more advanced stages of decay can have a larger mismatch in YOD dates. Consequently, we would not expect to see such a high correlation in paired YOD dates for all snags and logs at our study sites, particularly those missing their tags or those that were in advanced stages of decay having died before the PSPs were established. Nevertheless, the outcome of this analysis indicates that most YOD dates we obtained from crossdating closely represent the calendar year of a tree's outermost ring, making these samples suitable for comparison to the PSP IOD dates.

\section{Accuracy of YOD Estimates}

Comparison between the best YOD estimate and the IOD derived from repeated measures of permanent plots allowed us to assess the accuracy of our crossdating results in two ways: (1) by classifying each YOD date as accurate versus inaccurate and (2) by comparing the YOD date relative to the midpoint of its IOD. Overall, 59 of 100 YOD dates were classified as accurate, meaning the YOD estimate occurred within the documented IOD. Of the 41 inaccurate results, 39 YOD estimates preceded the observed IOD. Similarly, most $(77 \%)$ YOD dates preceded the IOD midpoints yielding positive accuracy errors. These skewed outcomes were unexpected. We had expected tree deaths would occur randomly through time so that accuracy errors would be evenly distributed around the IOD midpoints. Underlying this expectation, we assumed that tree deaths were caused by background mortality in absence of stand-level disturbances and the crossdated YOD dates had no systematic errors. Field records for the PSPs indicated windstorms and fires affected some PSPs, but not those included in our study. Therefore, we sought to understand the systematic underestimates of the YOD dates.

Consistent with the skewed frequency distributions, the regressions showed that accuracy error increased significantly with TSD, with subtle differences between genera. The general trend of decreased accuracy with time is consistent with well-documented processes of coarsewood decomposition. For the pine and spruce coarsewood that we studied, decay progresses from loss of needles, branches and bark to decay of the sapwood and heartwood (Newberry et al. 2004; DeLong et al. 2005, 2008; Powell et al. 2009). Different parts of the bole can decay at different rates, so even snags and logs in advanced stages of decay may have solid sections that can be dated accurately. However, as wood decomposes and outer rings are lost through time, the accuracy of crossdated YOD estimates decreases (Dynesius and Jonsson 
1991; Daniels et al. 1997). For spruce in our study area, there appears to be $c a$. 17-year lag after death before ring loss causes predictable errors in YOD estimates and corrections were modest (e.g. +2 and +5 years after 25 and 50 years, respectively). In contrast, corrections improved accuracy for pine YOD dates regardless of time since death and the corrections were more substantive (e.g. $+4,+7$ and +11 after 5,25 and 50 years, respectively). These results may indicate more rapid onset of decay and loss of the outer rings of pine relative to spruce, although our previous research did not detect differences in decay rates between genera for logs that had been dead $<50$ years (Jones 2009; Powell et al. 2009). Alternatively, this difference may relate to the unexpected, high frequency of accuracy errors for trees that died during the 1990-2000s. Most pines (12 of 18), but only some spruces (3 of 16), had YOD estimates that preceded the 1999, 2004 and 2005 IOD midpoints by up to 30 years. Because these snags and logs were not in advanced stages of decay, these inaccuracies suggest that some trees in our study had not formed rings in the years prior to death.

\section{Sources of Error in YOD Estimates}

The observed imprecision and inaccuracy in the YOD dates were attributed to combinations of several potential factors: (1) missing bark, (2) decayed sapwood, (3) highly suppressed outer rings, (4) asymmetrical cambial mortality, (5) lags between cessation of ring formation and tree death, (6) crossdating errors, and (7) errors in PSP data. The first two factors relate to sample quality caused by the stage of decomposition of the coarsewood. Although we attempted to sample all snags and logs using only radii that included bark and sound sapwood, poor sample quality caused by decomposition explains some discrepancies in pairs of YOD dates and crossdating inaccuracies. Consistent with our sampling protocols, only $6 \%$ of spruce and $15 \%$ of pine snags were missing bark or showed signs of decayed sapwood when processed in the lab. Low sample quality may be a more significant cause of error for logs, as $33 \%$ of spruce and $54 \%$ of pine logs were in advanced stages of decay and identifying two high-quality radii with bark and sound sapwood was difficult or not possible. For the latter logs, we compromised and assessed radii from the least decayed and most intact part of the bole, but it contributed to imprecision within individuals. These outcomes illustrate the importance of supplementary assessments of sample quality, such as the presence of the bark or evidence of sapwood decay, when estimating YOD dates from tree rings.

Tree growth prior to death can influence YOD estimates reconstructed using dendrochronology. Prolonged and severe radial growth suppression prior to death may result from competition and self-thinning in forests (Kozlowski et al. 1991; Takaoka 1993), senescence of old trees (Kelly et al. 1992; Larson et al. 1993), climatic variation causing stress (Villalba and Veblen 1998; Bigler et al. 2007; Drobyshev et al. 2007), damage caused by biotic disturbance (Cherubini et al. 2002), or combinations of these factors (Pederson 1998; Bigler et al. 2004). Highly suppressed outer rings are difficult to visually crossdate and measure (Mast and Veblen 1994). In extreme conditions, it is possible that trees do not allocate carbon to radial growth; thus, the calendar year of the outermost ring does not accurately indicate the year of tree death (Marchand 1984; Cherubini et al. 2002; Parent et al. 2002; Amoroso and Daniels 2010). Alternatively, stressed or declining trees may exhibit locally absent rings during periods of suppression (Mast and Veblen 1994; Cherubini et al. 2002) or asymmetrical cambial mortality (Kelly et al. 1992; Daniels et al. 1997; Amoroso and Daniels 2010) so that rings are incomplete around the circumference of the bole, resulting in imprecise or inaccurate YOD estimates.

In our study, most tree deaths seemed to result from stand-development processes including competition, self-thinning and senescence, because there was no record of stand-level biotic or abiotic disturbances affecting our study sites. In absence of specific disturbance agents (e.g. pathogens or insects), pine appeared to be more susceptible than spruce to stress that resulted in a cessation of ring formation prior to death and which led to the systematic underestimates of YOD by crossdating. 
Given these findings, we concur with recommendations that analysis of multiple increment cores or full cross-sections will increase the probability of determining the actual year of tree death using dendrochronology (Amoroso and Daniels 2010). For our study area, application of the generaspecific correction models can improve accuracy of crossdated YOD estimates, although additional work is needed to improve the spruce models to meet all statistical assumptions.

Lastly, human error also may have contributed to imprecision and inaccuracies. Although we used a combination of crossdating techniques and assigned outer-ring dates independently to each core, we cannot eliminate the possibility that some crossdating outcomes were incorrect. For some ring-width series, more than one potential outerring date was identified using COFECHA. We differentiated among possible outcomes using TSAP-Win statistics and graphics and by assessing the alignment of narrow and wide marker rings by visual crossdating (Cherubini et al. 2002). Nevertheless, incorrect YOD dates may have been assigned to some samples. Alternatively, mistakes while recording data in the field or entering the data in the lab would cause errors in the PSP records.

\section{Limitations of the PSP Data for Assessing Accuracy}

Although comparison of crossdated YOD dates with the PSP was insightful, it did have limitations that could be overcome in future research. Ideally, PSP re-measurements would be conducted consistently at short intervals (e.g. every 5 years) for results to be directly comparable through time. In this study, however, the PSP intervals varied from 5-34 years, with short intervals in the 1950-1960s and 1990-2000s $(<10$ years) but long intervals from the 1960 1990s (13-34 years). Given the large variation in interval lengths, we expected that accuracy would vary through time. Consistent with this expectation, accuracy of pine YOD dates was greater during the long intervals (19 of 27, 70\%) than the short intervals ( 1 of $9,11 \%$ in the $1950-1960$ s and 6 of $18,33 \%$ in the 1990-2000s). In contrast, for spruce, accuracy was greatest during the short intervals in the 1990-2000s (13 of 16, 81\%), followed by long intervals in the 1960-1990s (17 of $22,73 \%$ ), and least accurate during the short intervals in the 1950-1960s (4 of 8,50\%). This difference between genera is consistent with our interpretation that pine was more susceptible than spruce to cessation of ring formation prior to death.

\section{CONCLUSIONS AND RECOMMENDATIONS}

Crossdating provides annually-resolved estimates of YOD for snags and logs, but these outcomes are not always precise (consistent between samples from a single tree) and accurate (crossdated YOD is the actual year of death). Comparison of crossdated YOD dates for pairs of cores from snags or radii from logs showed that $90 \%$ of YOD estimates were within 10 years of each other, indicating a relatively high degree of precision for spruce and pine that had been dead $\leq 50$ years in our study area. For future studies based on a single radius from coarsewood, we recommend grouping YOD dates into classes that are at least 10-years wide to account for precision error.

Comparison of crossdated YOD dates with the IOD recorded in PSP records showed that accuracy was greater for spruce than pine in our study area. Correction models improved the accuracy of spruce YOD estimates only for trees that had been dead $\geq 17$ years and the resulting corrections were modest (e.g. +5 years after 50 years); however, these models have limited application beyond comparative analysis with pine because they did not meet the assumption of normality. Cessation of ring formation prior to death, likely caused by competition and senescence, was more prevalent in pine, resulting in correction models that improved accuracy of YOD dates regardless of when trees died and more substantive corrections through time (e.g. +4 and +11 years after 5 and 50 years, respectively). We recommend using the error correction model for pine coarsewood in similar environments and urge others to develop genus- and environmentspecific corrections when possible. 
Precision and accuracy errors resulted from many factors including loss of bark, wood decay, lack of ring formation around the bole caused by stress prior to death, and human error. Our results reinforce the need for multiple lines of evidence when reconstructing tree deaths using tree rings. In general, precision and accuracy of crossdated YOD estimates can be improved by (1) assessing only radii that include bark and sapwood, (2) assessing multiple radii around the bole of coarsewood, (3) verifying crossdating outcomes with supplemental field notes on snag or log morphology, such as decay class or presence of bark and sapwood, (4) considering the cause of tree death and its potential impacts on ring formation prior to death, and (5) using multiple crossdating techniques. Ideally, when comparing crossdating outcomes to data from PSPs, the re-measurement intervals would be short and consistent, maximizing comparability through time. This would also facilitate comparisons among genera and locations.

\section{ACKNOWLEDGMENTS}

Thanks to R. Bonar and G. Buckmaster of Hinton Wood Products for providing the permanent sample plot data, A. Nicoll, J. Amerongen Maddison, E. Henderson, A. Parajulee, K. McLeod, and R. Chavardes for their assistance in the field and lab, and M. Amoroso, V. LeMay, R. D. Moore, F. Lombardi and C. Bigler who provided helpful comments on the manuscript. This research was funded by a grant from the Collaborative Research and Development Program of the Natural Sciences and Engineering Research Council of Canada, Foothills Research Institute Natural Disturbance Program, Hinton Wood Products - West Fraser Mills Ltd. and Alberta Newsprint Company and an NSERC Scholarship to E. Jones.

\section{REFERENCES CITED}

Amoroso, M. M., and L. D. Daniels, 2010. Cambial mortality in declining Austrocedrus chilensis forests: Implications for stand dynamics studies. Canadian Journal of Forest Research 40:885-893.

Beckingham, J. D., I. W. G. Corns, and J. H. Archibald, 1996. Field Guide to Ecosites of West-Central Alberta. Canadian Forest Service, Northwest Region, Edmonton, AB.
Bigler, C., D. G. Gavin, C. Gunning, and T. T. Veblen, 2007. Drought induces lagged tree mortality in a subalpine forest in the Rocky Mountains. Oikos 116:1983-1994.

Bigler, C., J. Gricar, H. Bugmann, and K. Cufar, 2004. Growth patterns as indicators of impending tree death in silver fir. Forest Ecology and Management 199:183-90.

Cherubini, P., G. Fontana, D. Rigling, M. Dobbertin, P. Brang, and J. L. Innes, 2002. Tree-life history prior to death: Two fungal root pathogens affect tree-ring growth differently. Journal of Ecology 90:839-50.

Cook, E. R., 1985. A Time Series Analysis Approach to TreeRing Standardization. Ph.D. dissertation, University of Arizona, Tuscon, Arizona.

Daniels, L. D., J. Dobry, K. Klinka, and M. C. Feller, 1997. Determining year of death of logs and snags of Thuja plicata in southwestern coastal British Columbia. Canadian Journal of Forest Research 27:1132-1141.

DeLong, S. C., L. D. Daniels, B. Heemskerk, and K. O. Storaunet, 2005. Temporal development of decaying log habitats in wet spruce-fir stands in east-central British Columbia. Canadian Journal of Forest Research 35:28412850.

DeLong, S. C., G. D. Sutherland, L. D. Daniels, B. H. Heemskerk, and K. O. Storaunet, 2008. Temporal dynamics of snags and development of snag habitats in wet spruce-fir stands in east-central British Columbia. Forest Ecology and Management 255:3613-3620.

Drobyshev, I., H. Linderson, and K. Sonesson, 2007. Temporal mortality pattern of penduculate oaks in southern Sweden. Dendrochronologia 24:97-108.

Dynesius, M., and B. G. Jonsson, 1991. Dating uprooted trees: comparison and application of eight methods in a boreal forest. Canadian Journal of Forest Research 21:655-665.

Fritts, H. C., 1976. Tree Rings and Climate. Academic Press, New York, New York.

Grissino-Mayer, H. D., 2001. Evaluating crossdating accuracy: A manual and tutorial for the computer program COFECHA. Tree-Ring Research 57:205-221.

Harmon, M. E., J. F. Franklin, F. J. Swanson, P. Sollins, S. V. Gregory, J. D. Lattin, N. H. Anderson, S. P. Cline, N. G. Aumen, J. R. Sedell, G. W. Lienkaemper, K. Cromack, and K. W. Cummins, 1986. Ecology of coarse woody debris in temperate ecosystems. Advances in Ecological Research 15: 133-302.

Hinton Wood Products, 2006. Permanent Growth Sample Program Manual, Version 16. West Fraser Mills Ltd., Hinton, Alberta, Canada.

Holmes, R. L., 1983. Computer-assisted quality control in treering dating and measuring. Tree-Ring Bulletin 43:69-78.

Jones, E. L., 2009. Decay Dynamics of Coarsewood Habitat in Old-Growth Spruce and Pine Stands in the Rocky Mountain Foothills. M.Sc. thesis, University of British Columbia, Vancouver, BC.

Keeland, B. D., and R. R. Sharitz, 1993. Accuracy of tree growth measurements using dendrometer bands. Canadian Journal of Forest Research 23:2454-2457.

Kelly, P. E., E. R. Cook, and D. W. Larson, 1992. Constrained growth, cambial mortality, and dendrochronology of ancient 
Thuja occidentalis on cliffs of the Niagara escarpment - an eastern version of the bristlecone pine. International Journal of Plant Sciences 153:117-127.

Kozlowski, T. T., P. J. Kramer, and S. G. Pallady, 1991. The Physiological Ecology of Woody Plants. Academic Press, Inc., San Diego, New York, Boston, London, Sydney, Tokyo, Toronto.

Larson, D. W., U. Matthes-Sears, and P. E. Kelly, 1993. Cambial dieback and partial shoot mortailty in cliff-face Thuja occidentalis: Evidence for sectored radial architecture. International Journal of Plant Science 154:496-505.

Lewis, S. L., O. L. Phillips, D. Sheil, B. Vinceti, T. R. Baker, S. Brown, A. W. Graham, N. Higuchi, D. W. Hilbert, W. F. Laurance, J. Lejoly, Y. Malhi, A. Monteagudo, P. N. Vargas, B. Sonke, N. Supardi, J. W. Terborgh, and R. V. Martinez, 2004. Tropical forest tree mortality, recruitment and turnover rates: Calculation, interpretation and comparison when census intervals vary. Journal of Ecology 92:929-944.

Marchand, P. J., 1984. Dendrochronology of a fir wave. Canadian Journal of Forest Research 14:51-56.

Maser, C., R. G. Anderson, K. Cromack, J. T. Williams, and R. E. Martin, 1979. Dead and down woody material. In Wildlife Habitats in Managed Forests: the Blue Mountains of Oregon and Washington, edited by J. W. Thomas, pp. 78-95. USDA Forest Service, Agriculture Handbook No. 553. USDA Forest Service, Washington, DC.

Mast, J. N., and T. T. Veblen, 1994. A dendrochronological method of studying tree mortality patterns. Physical Geography 15:529-542.

Morgantini, L. E., and J. L. Kansas, 2003. Differentiating mature and old-growth forests in the Upper Foothills and subalpine subregions of west-central Alberta. Forestry Chronicle 79:602-612.

Neter, J., M. Kutner, H. C. J. Nachtsheim, and W. Wasserman, 1996. Applied Linear Statistical Models, 4th ed. McGraw-Hill, Boston, Massachusetts.

Newberry, J. E., K. J. Lewis, and M. B. Walters, 2004. Estimating time since death of Picea glauca $\times P$. engelmannii and Abies lasiocarpa in wet cool sub-boreal spruce forest in east-central British Columbia. Canadian Journal of Forest Research 34:931-938.
Nord-Larsen, T., 2006. Modeling individual-tree growth from data with highly irregular measurement intervals. Forest Science 52:198-208.

Parent, S., H. Morin, and C. Messier, 2002. Missing growth rings at the trunk base in suppressed balsam fir saplings. Canadian Journal of Forest Research 32:1776-1783.

Pedersen, B. S., 1998. The role of stress in the mortality of Midwestern oaks as indicated by growth prior to death. Ecology 79:79-93.

Powell, S. R., L. D. Daniels, and T. A. Jones, 2009. Temporal dynamics of large woody debris in small streams of the Alberta foothills, Canada. Canadian Journal of Forest Research 39:1159-1170.

Rinn, F., 2003. TSAP-Win User Reference. Rinntech, Heidelberg, Germany.

Stokes, M. A., and T. L. Smiley, 1996. An Introduction to TreeRing Dating, 2nd ed. University of Arizona Press, Tuscon.

Storaunet, K. O., and J. Rolstad, 2004. How long do Norway spruce snags stand? Evaluating four estimation methods. Canadian Journal of Forest Research 34:376-383.

Takaoka, S., 1993. The effect of missing rings on stand-age estimation of even-aged forests in northern Hokkaido, Japan. Ecological Research 8:341-347.

Thomas, J. W., R. G. Anderson, C. Maser, and E. L. Bull, 1979. Snags. In Wildlife Habitats in Managed Forests: the Blue Mountains of Oregon and Washington, edited by J. W. Thomas, pp. 60-77. USDA Forest Service, Agriculture Handbook No. 553, Washington, DC.

Vanderwel, M. C., J. R. Malcolm, and S. M. Smith, 2006. An integrated model for snag and downed woody debris decay class transitions. Forest Ecology and Management 234:48-59.

Villalba, R., and T. T. Veblen, 1998. Influences of large-scale climatic variability on episodic tree mortality in northern Patagonia. Ecology 79:2624-2640.

Received 11 October 2010; accepted 25 September 2011. 